\title{
Effects of change in stimulus duration on amplitude of the electrodermal orienting response
}

\author{
DAVID A. T. SIDDLE, CHRIS KYRIACOU, and PETER A. HERON \\ University of Southampton, Southampton $\mathrm{SO} 9 \mathrm{NH}$, England
}

\begin{abstract}
This paper presents two experiments which investigated amplitude of the skin conductance response (SCR) component of the orienting response to decreases in stimulus duration. Experiment 1 employed auditory stimuli, while visual stimuli were used in Experiment 2. In Experiment $1(\mathrm{~N}=60)$, experimental subjects received 6,12 , or 18 presentations of a $1,000-\mathrm{Hz}$, 70-dB training stimulus of 15 sec duration, followed by a test trial on which stimulus duration was $5 \mathrm{sec}$. Control subjects received 19 training trials. There were no differences in responsiveness on the test trial between the control group on the one hand and experimental groups on the other. In Experiment $2(\mathrm{~N}=60)$, half the subjects received 15 presentations of a 5 -sec patterned visual stimulus, while for the other half, the stimulus was nonpatterned. Within each of these groups, stimulus duration was reduced to $1 \mathrm{sec}$ on Trial 16 (test trial) for half of the subjects. The results indicated that experimental subjects displayed significantly larger test trial SCRs than did control subjects, regardless of whether the stimulus was patterned or nonpatterned.
\end{abstract}

According to Sokolov (1963), two stages are involved in elicitation of the orienting response (OR) following habituation training. In the first, afferent stimulation is compared with the stored characteristics of previous stimulation, while in the second, the $\mathrm{OR}$ is either elicited or inhibited, depending upon the results of the comparison process. Storage is said to occur in a "neuronal model" and a match between afferent stimulation and this model leads to OR suppression, while a mismatch leads to OR expression.

Sokolov's model is based on his data which indicated that after a number of stimulus repetitions, a discriminable change in sensory input resulted in an increase in OR amplitude. Subsequently, OR amplitude to a change in stimulation has been examined by a number of authors who have employed intensity changes in visual and auditory stimuli, pitch changes in auditory stimuli, stimulus omission, and changes in the order of stimulus presentation. Although Graham (1973) has concluded that the results of these studies are generally consistent with Sokolov's model, O'Gorman (1973) has argued that the only change conditions which reliably result in an increase in OR amplitude are increases in stimulus intensity and

This research was supported by Grant B/RG/44047 from the Science Research Council. Address requests for reprints to: D. A. T. Siddle, Ph.D., Department of Psychology, University of Southampton, SO9 5NH, England. The second author is now at the Department of Education, Cambridge University, and the third author is at the Napier College of Commerce and Technology, Edinburgh. changes in stimulus modality. He has argued that these data can be interpreted more parsimoniously using an arousal construct rather than one of stimulus matching. One condition which has received little systematic investigation is that of change in stimulus duration, and OR recovery following such changes has not been unequivocally demonstrated. ${ }^{1}$ It is with the effects of change in stimulus duration on the skin conductance response (SCR) component of the OR that the present paper is concerned.

Koepke and Pribram (1966) reported that following habituation training to a criterion of three consecutive response failures, a change in stimulus duration from 2 to $20 \mathrm{sec}$ or from 20 to $2 \mathrm{sec}$ produced SCR recovery in $49 \%$ of subjects. That subjects were responding to stimulus change per se and not to stimulus onset was demonstrated by the fact that response latencies were significantly longer on the change (test) trial than on those occurring during habituation training. However, the stimulus intensity employed by Koepke and Pribram (1966) was 94 dB, and it is likely, therefore, that the defense response rather than the OR was being studied. Moreover, the number of subjects who responded to the duration increase and decrease, respectively, was not reported. Stimuli in the OR-eliciting range were employed by Geer (1967), who investigated the effects of a 2to 12-sec change in stimulus duration on the SCR. Again, responsiveness to stimulus change was demonstrated by an increase in response latency. However, since test-trial SCR amplitude was not compared with either a control condition not involv- 
ing stimulus change or pretest response level, it cannot be concluded that a change in stimulus duration leads to OR recovery. Positive results were obtained by Van Olst (1971), who employed a variety of duration change conditions and who reported that SCR amplitude was larger on the test trial than on the last training trial in $80 \%$ of subjects. However, a comparison of test and last training trial response amplitudes was made only for those subjects who displayed a measurable test trial response.

The present paper reports the results of two studies designed to investigate recovery of the electrodermal $O R$ to a change in stimulus duration. Since an increase in stimulus duration involves an increase in stimulus energy, the effects of stimulus change are confounded, at least in this situation, with the effects of dynamogenic factors. Accordingly, the present studies employed a decrease in stimulus duration.

\section{EXPERIMENT 1}

This experiment was designed to investigate the effects of number of training trials on recovery of the SCR to a decrease in auditory stimulus duration. Sokolov's analysis of OR habituation suggests that the precision of the neuronal model increases as a positive function of the number of training trials, and it can be argued (Geer, 1967; Siddle \& Heron, 1975) that a change in stimulation which occurs late in training will result in a greater mismatch between afferent stimulation and the neuronal model than will one which occurs relatively early in training. In the present study, experimental subjects received 6,12 , or 18 training trials prior to the test trial, while a control group received 19 training trials. It was predicted that in each of the experimental groups, test trial SCR amplitude would be significantly larger than on the corresponding training trial in the control group, and that test trial response amplitude would be a positive function of the number of previous training trials.

\section{Method}

Subjects. The subjects were 60 undergraduate volunteers (age range: 17-24 years) who were allocated randomly to one of four groups with the restriction that all groups contain the same proportion of males and females. There were nine men and six women in each group. The records of three subjects who failed to display any evoked SCRs were discarded, and three more subjects were recruited from the same population.

Apparatus and Procedure. The training stimulus was a $1,000 \mathrm{~Hz}$ tone of $15 \mathrm{sec}$ duration, presented at randomly ordered intervals of $20,30,40$, and $50 \mathrm{sec}$ (offset to onset). Tone intensity was $70 \mathrm{~dB}$ (re: $.0002 \mathrm{dyne} / \mathrm{cm}^{2}$ ) as rated by a sound-level meter (Dawe Instruments Ltd.) at the headrest of the chair in which subjects sat, while the rise time was $30 \mathrm{msec}$. The test stimulus was a $1,000 \mathrm{~Hz}, 70-\mathrm{dB}$ tone of $5 \mathrm{sec}$ duration. All stimuli were produced by an Advance signal generator (Model H1B) and delivered through a speaker $100 \mathrm{~cm}$ directly behind the subject. Stimulus duration was controlled by a Birkbeck timer.
Bipolar recording of skin conductance was made using domed $\mathrm{Ag}-\mathrm{AgCl}$ electrodes filled with $0.05 \mathrm{M} \mathrm{NaCl}$ electrolyte and attached to masked areas on the index and second fingers of the subject's left hand. The electrodes were placed over the whorls of the fingerprints on the distal phalanges. A constant voltage of $0.5 \mathrm{~V}$ (Lykken \& Venables, 1971) was applied across the electrodes, and conductance was recorded on a Grass Model 7 polygraph with a 7P1 B preamplifier sensitivity of $1 \mathrm{~mm}$ of pen deflection equal to $0.02 \mu \mathrm{mhos}$. Respiration was recorded using a Grass nasal thermocouple to detect changes in conductance arising from respiratory irregularities.

The subjects were seated in a semireclining padded chair in a soundproof room, and the apparatus was monitored from an adjoining room. They were informed that, after a short rest period, some tones would be heard from time to time and that no responses were required. They were asked to relax but not to go to sleep. After a 5-min rest period, the stimulus program commenced without prior warning. Group 1 received 6 training trials, Group 2 received 12, Group 3 received 18, and control subjects (Group C) received 19. Groups 1, 2, and 3 received one presentation of the test stimulus on Trials 7,13 , and 19, respectively.

The subjects were tested under eyes-closed conditions with an ambient room illumination of 2 lux. Temperature was within the range $19^{\circ}-24^{\circ} \mathrm{C}$, and the relative humidity was within the range $49 \%-55 \%$.

Scoring. Both onset and offset responses were scored on habituation trials and on the test trial. Any artifact-free SCR greater than $0.02 \mu$ mhos occurring from $1-5$ sec after stimulus onset was considered a change evoked by stimulus onset, while any SCR greater than $0.02 \mu$ mhos which occurred $1-5 \mathrm{sec}$ following stimulus offset was considered a change evoked by stimulus offset. Tonic skin conductance level (SCL) and spontaneous activity were assessed during the rest period. SCL was measured at each minute, and mean rest period SCL was expressed in terms of log ( $\mu$ mhos $\times 10$ ), while spontaneous activity was measured by counting the number of artifact-free fluctuations greater than $0.02 \mu \mathrm{mhos}$.

\section{Results and Discussion}

There were no group differences in terms of rest period $\operatorname{SCL}[\mathrm{F}(3,56)=2.08]$, number of spontaneous fluctuations $[F(3,56)=2.69]$, or $\sqrt{S C R}$ amplitude on the first training trial $[F(3,56)=1.15]$.

The original intention was to assess OR recovery for each experimental group by comparing the amplitude of offset responses on the test trial with the amplitude of the offset responses on the appropriate training trial for Group C. The effect of number of training trials on recovery could then have been examined by comparing test trial responsiveness between experimental groups. Such analyses could not be performed, however, since too few of the experimental subjects displayed measurable offset responses on the test trial. Table 1 shows the number of experimental and control subjects who displayed measurable onset and offset responses on the test trial, together with the number of onset and offset responses displayed on the last training trial. It can be seen that although the experimental and control groups displayed comparable responsiveness in terms of onset responses, the number of test trial offset SCRs displayed by experimental subjects was extremely small and barely larger than the number displayed by Group C. Moreover, the number of test trial offset responses displayed by experimental sub- 
Table 1

Number of Onset and Offset SCRs Displayed by Experimental and Control Subjects on Test Trials and on the Last Training Trial

\begin{tabular}{|c|c|c|c|c|c|c|c|c|c|c|c|c|}
\hline & \multicolumn{6}{|c|}{ Test Trial } & \multicolumn{6}{|c|}{ Last Training Trial } \\
\hline & \multicolumn{6}{|c|}{ Group } & \multicolumn{6}{|c|}{ Group } \\
\hline & 1 & $\mathrm{C}$ & 2 & C & 3 & $\mathrm{C}$ & 1 & $\mathrm{C}$ & 2 & $\mathrm{C}$ & 3 & $\mathrm{C}$ \\
\hline Onset & 7 & 8 & 7 & 7 & 8 & 5 & 8 & 7 & 7 & 7 & $\begin{array}{l}7 \\
2\end{array}$ & $\begin{array}{l}6 \\
2\end{array}$ \\
\hline Offset & 2 & 3 & 3 & 1 & 3 & 2 & 3 & 4 & 2 & 1 & 2 & \\
\hline
\end{tabular}

jects was similar to the number of offset responses displayed by both control and experimental subjects on the last training trial.

Although the above results provide no evidence of SCR recovery to a decrease in auditory stimulus duration, it could be argued that response interference was a confounding factor. Response interference effects are well documented (Grings \& Schell, 1969), and it is possible that SCRs elicited by test stimulus offset interfered with the occurrence of responses elicited by the change in stimulus duration. However, the frequency of offset responses in all groups during training was extremely low (Table 1), and, on this basis, it seems difficult to sustain the interference argument.

Although the data concerning the effect of stimulus duration on SCR habituation are contradictory (see Graham, 1973), previous work in this laboratory (Spinks \& Siddle, 1976) has indicated that habituation is sensitive to the duration of complex visual stimuli. On this basis, it seems reasonable to ask whether SCR recovery is sensitive to changes in the duration of complex visual stimuli. Experiment 2 was designed to investigate this issue.

\section{EXPERIMENT 2}

This experiment was designed to investigate the effect of change in visual stimulus duration on SCR recovery. Half the subjects received a number of presentations of a black and white patterned visual stimulus, while for the other half, the stimulus was nonpatterned. Within each of these groups, half the subjects received a stimulus of shorter duration on the test trial (experimental subjects), while the other half received a further presentation of the training stimulus (control subjects).

\section{Method}

Subjects. The subjects were 60 additional undergraduate volunteers (age range: 17-24 years), who were allocated randomly to one of the four groups with the restriction that all groups contain the same proportion of males and females. There were nine men and six women in each group.

Apparatus and Procedure. The patterned stimulus was the most complex of those used by Spinks and Siddle (1976). It was con- structed from a 35 by 25 matrix and contained 60 bits of information. The construction of the stimulus and the determination of information content have been described by Attneave (1954). The luminance of the black area was $21.6 \mathrm{~cd} / \mathrm{m}^{2}$, while that of the white area was $137.2 \mathrm{~cd} / \mathrm{m}^{2}\left(\bar{X}=79.4 \mathrm{~cd} / \mathrm{m}^{2}\right)$. The luminance of the nonpatterned stimulus was $79.4 \mathrm{~cd} / \mathrm{m}^{2}$. All stimuli were backprojected by a Gaf 603 projector onto a ground-glass screen situated $200 \mathrm{~cm}$ directly in front of the subjects. The projected area was $24 \times 17 \mathrm{~cm}$. Stimulus duration was $5 \mathrm{sec}$ during training, and stimuli were presented at randomly ordered intervals of $20,30,40$, and $50 \mathrm{sec}$ (offset to onset). Experimental subjects received 15 training trials followed by a test trial on which stimulus duration was $1 \mathrm{sec}$, while control subjects received 16 training trials. At the end of the testing session, all subjects received one presentation of a $1,000-\mathrm{Hz}, 100-\mathrm{dB}$ tone of $1 \mathrm{sec}$ duration. Responses to this stimulus were used for range-correcting test trial responses (Lykken \& Venables, 1971).

The control of stimulus presentation, recording techniques, and the experimental procedure were the same as in Experiment 1.

Scoring. During habituation training, any artifact-free SCR greater than $0.02 \mu \mathrm{mhos}$, occurring from 1 to $5 \mathrm{sec}$ after stimulus onset, was considered a change evoked by the stimulus. This criterion was also used for control subjects on Trial 16. For experimental subjects, however, test trial responses were scored only if they occurred within 1 to $5 \mathrm{sec}$ following stimulus offset (i.e., 2-6 sec following stimulus onset). Rest period SCL and spontaneous fluctuations were scored in the same manner as in Experiment 1.

\section{Results}

There were no group differences in terms of rest period SCL $[F(3,56)=1.82]$, number of spontaneous fluctuations $[\mathrm{F}(3,56)<1]$ or $\sqrt{\mathrm{SCR}}$ amplitude on the first training trial $[F(3,56)=1.64]$.

Test trial responses were analyzed using a two-way analysis of variance in which the main factors were groups (experimental vs. control) and stimulus type (patterned vs. nonpatterned). The data were first range-corrected and subjected to a square root transformation. There was a reliable effect for groups $[F(1,56)=14.81, p<.01]$, but neither the stimulus type factor $[F(1,56)<1]$ nor the Stimulus by Group interaction $[F(1,56)<1]$ was significant. Experimental subjects displayed significantly larger test trial SCRs than did control subjects, regardless of whether the stimulus was patterned or nonpatterned. Figure 1 shows mean response amplitude for the four groups plotted against blocks of training trials and on the test trial. As a further check that the experimental subjects' test trial responses were to the changes in stimulus duration, the latency of these responses was compared with response latency on the last training trial on which an SCR occurred (Koepke \& Pribram, 1966). Since this was a within-subjects comparison, a test for correlated samples (Sandler's A) was employed. Test trial response latency $(\bar{X}=$ $2.66 \mathrm{sec}, \mathrm{SD}=0.63)$ was significantly longer $(\mathrm{A}=$ $0.096, \mathrm{p}<.001)$ than that during training $(\overline{\mathrm{X}}=$ $1.90 \mathrm{sec}, \mathrm{SD}=0.65$ ).

Although these results seem to indicate SCR recovery to a decrease in visual stimulus duration, the results could have been confounded by either re- 


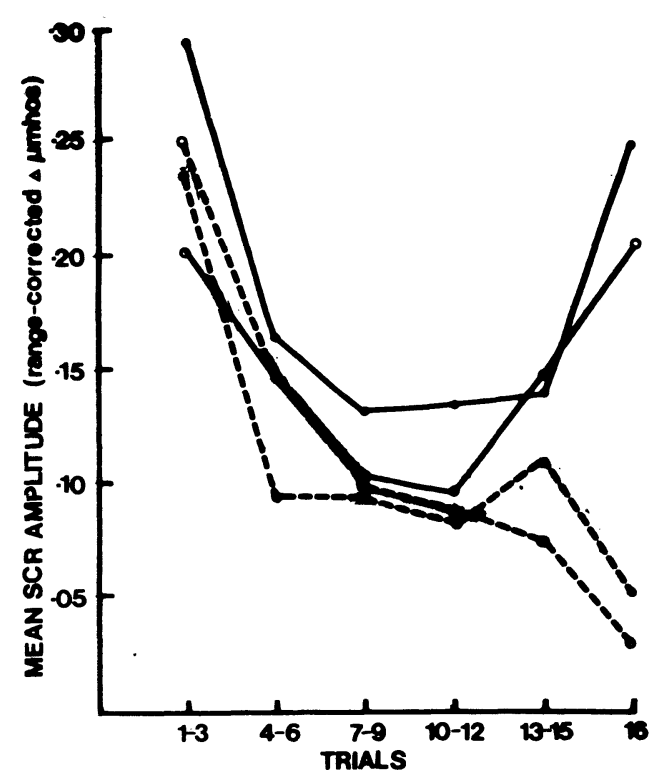

Figure 1. Mean range-corrected SCR amplitude plotted against blocks of habituation trials and on the test trial. Experimental group-patterned $(\bullet-\bullet)$; experimental group-blank $(\mathrm{O}-\mathrm{O})$; control group-patterned $(\bullet----\bullet)$; control group-blank $\left(\mathrm{O}_{-}---\mathrm{O}\right)$.

sponse interference (Grings \& Schell, 1969) or response summation (Furedy \& Ginsberg, 1975). Response interference seems unlikely in view of the low frequency of offset responses observed, and, in any event, such an effect would have been operating against SCR recovery. ${ }^{2}$ With regard to the summation effect, the test stimulus and the change in stimulus duration could be regarded as two stimuli, and Furedy and Ginsberg (1975) have reported that two stimuli which are presented with a short ISI $(450 \mathrm{msec}$ offset to onset) produce larger SCRs than does one of the stimuli presented alone. However, of the 24 experimental subjects in the present study who displayed a measurable change in conductance on the test trial, 10 subjects displayed two SCRs; the first was interpreted as a response to stimulus onset and the second as a response to stimulus change. The remaining 14 subjects displayed only a single test trial response, and all of these were within the latency period for a response-to-stimulus change (i.e., 1-5 sec after stimulus offset). Although it might be argued that these were long-latency SCRs to stimulus onset, it is difficult to see why they should be significantly larger than the test trial responses displayed by control subjects.

\section{GENERAL DISCUSSION}

The results of Experiment 2 seem to indicate that a decrease in visual stimulus duration leads to recov- ery of the SCR component of the OR. This finding held regardless of whether the stimulus was patterned or nonpatterned. The results are consistent with predictions derived from Sokolov's (1963) model of the OR, but it might be argued that they can also be explained in terms of dual-process theory (Groves \& Thompson, 1970; Thompson \& Spencer, 1966). According to Thompson and Spencer (1966), recovery to stimulus change is an instance of incomplete generalization of habituation, and the extent to which recovery occurs is an inverse function of the degree of overlap between the neural pathways activated by the habituation and change stimuli. In the case of a change in stimulus duration, however, the test stimulus would presumably activate the same pathways as activated by the training stimulus. On this basis, it is difficult to see how SCR recovery in this situation can be explained in terms of partial overlap of activated pathways. It would appear that a decrease in stimulus duration is somewhat similar to a situation in which a stimulus is omitted completely in that subjects are responding to the absence of at least part of a stimulus. In these terms, a stimulus-matching model of the type proposed by Sokolov (1963) may provide a more satisfactory explanation of the data.

A puzzling aspect of the results concerns the SCR recovery obtained to a change in visual stimulus duration and the lack of recovery to a change in the duration of an auditory stimulus. Perhaps one explanation of this discrepancy might be made in terms of alertness differences between the experiments. In the case of visual stimuli where subjects were tested under eyes-open conditions, perception of the stimulus would presumably require a number of "observing responses" (Mackworth, 1969), both during the rest period and during habituation training. This would not be the case for auditory stimulation where subjects were tested under eyes-closed conditions, and it might be expected that the subjects' level of alertness would be higher in Experiment 2 than in Experiment 1. An attempt was made to examine this possibility by comparing tonic SCL and frequency of spontaneous fluctuations from the rest periods of Experiments 1 and 2. Both SCL $[\mathrm{F}(1,118)=181.73$, $\mathrm{p}<.01]$ and spontaneous activity $[\mathrm{F}(1,118)=21.92$, $\mathrm{p}<.01]$ were significantly higher in Experiment 2 than in Experiment 1. Mean rest period SCL in Experiment 1 was $1.41 \log (\mu$ mhos $\times 10)(\mathrm{SD}=$ 0.198), while that in Experiment 2 was 1.94 (SD = 0.231 ). The mean number of spontaneous fluctuations displayed during the rest period in Experiment 1 was $15.83(\mathrm{SD}=14.43)$, while that in Experiment 2 was $31.15(\mathrm{SD}=20.83)$. Moreover, SCL immediately prior to the test stimulus was significantly higher in the experimental groups in Experiment 2 than in each of the three experimental groups in Experiment 1 [F ratios $(1,43)$ from 40.90 to 67.02 , 
$\mathrm{p}<.01]$. Thus, these post hoc analyses provide some evidence that subjects in Experiment 2 were more alert, both during the rest period and prior to the test trial, than were those in Experiment 1, and it is possible that this difference resulted from the different modalities used. However, a confounding variable is the fact that Experiments 1 and 2 were conducted by different experimenters. ${ }^{3}$ In view of the evidence that subject-experimenter interaction can influence physiological responsivity (Christie \& Todd, 1975), it is possible that this factor was responsible for the tonic level differences between the two experiments. What seems to be required is an experiment in which both auditory and visual stimuli are employed and in which subjects receiving auditory stimuli are tested under both eyes-open and eyes-closed conditions.

In any event, an explanation of the discrepancy between the results of Experiments 1 and 2 in terms of alertness differences raises a further problem. This concerns the effect of arousal on response to stimulus change. Although the effects of arousal on habituation are well-documented (e.g., Carroll \& Pokora, 1976), similar effects on response to stimulus change have not been systematically investigated. If some sort of amplifying or arousal system is considered to be important in elicitation of the OR (Sokolov, 1963), response output might be a function of the interaction between tonic activity in the amplifying system and any phasic increase produced by the change (test) stimulus. It could be that in a situation in which the test stimulus does not produce a phasic increase in activity in the amplifying system (e.g., stimulus omission and decreases in stimulus duration), a certain threshold level of tonic activity is necessary for response output. However, this argument is speculative, and an investigation of the effects of arousal on response to stimulus change seems both necessary and desirable.

One final aspect of the results deserves comment. While Spinks and Siddle (1976) reported habituation differences between subjects exposed to simple and complex visual stimuli, no such differences were apparent here. However, subjects in the Spinks and Siddle study were "extrinsically" motivated in that they were told that they would be required to recognize the stimulus at the end of the experiment, and this presumably resulted in greater stimulus "significance" (Bernstein, 1969). The subjects in the present study did not receive such instructions, and this difference in procedure probably accounts for the different results.

\section{REFERENCES}

Attneave, F. Some informational aspects of visual perception. Psychological Review, 1954, 61, 183-193.

Bernstein, A. S. To what does the orienting response respond? Psychophysiology, 1969, 6, 338-350.
Carroll, D., \& Pokora, J. The effects of threat of shock on SCR habituation to simple auditory stimuli. Physiological Psychology, 1976, 4, 94-96.

Christie, M. J., \& Todd, J. L. Experimenter-subjects-situational interactions. In P. H. Venables \& M. J. Christie (Eds.), Research in psychophysiology. London: Wiley, 1975. Pp. 50-68.

Furedy, J. J., \& Ginsberg, S. Test of an orienting-reactionrecovery account of short-interval autonomic conditioning. Biological Psychology, 1975, 3, 121-129.

GEER, J. H. Some basic parameters of the orienting response. In I. Ruttkay-Nedecky, L. Ciganek, V. Zikmund, \& E. Kellerova (Eds.), Mechanisms of orienting reaction in man. Bratislava: Slovak Academy of Sciences, 1967. Pp. 237-243.

GraHAM, F. K. Habituation and dishabituation of responses innvervated by the autonomic nervous system. In $\mathrm{H}$. V. S. Peeke \& M. J. Herz (Eds.), Habituation (Vol. 1) Behavioral studies. New York: Academic Press, 1973. Pp. 163-218.

Grings, W. W., \& Schell, A. M. Magnitude of electrodermal response to a standard stimulus as a function of intensity and proximity of a prior stimulus. Journal of Comparative and Physiological Psychology, 1969, 67, 77-82.

Groves, P. M., \& Thompson, R. F. Habituation: A dualprocess theory. Psychological Review, 1970, 77, 419-450.

Koepke, J. E., \& Pribram, K. H. Habituation of GSR as a function of stimulus duration and spontaneous activity. Journal of Comparative and Physiological Psychology, 1966, 61, 442-448.

LyKKen, D. T., \& Venables, P. H. Direct measurement of skin conductance: A proposal for standardization. Psychophysiology, 1971, 8, 656-672.

MACKWORTH, J. F. Vigilance and habituation. Harmondsworth: Penguin, 1969.

O'Gorman, J. G. Change in stimulus conditions and the orienting response. Psychophysiology, 1973, 10, 465-470.

Siddle, D. A. T., \& Heron, P. A. Stimulus omission and recovery of the electrodermal and digital vasoconstrictive components of the orienting response. Biological Psychology, 1975, 3, 277-293.

Sokolov, E. N. Perception and the conditioned reflex. Oxford: Pergamon, 1963.

SpINKS, J. A., \& Siddle, D. A. T. Effects of stimulus information and stimulus duration on amplitude and habituation of the electrodermal orienting response. Biological Psychology, 1976, 4, 29-39.

STERN, J. A. Toward a developmental psychophysiology: My look into the crystal ball. Psychophysiology, 1968, 4, 403-420.

Thompson, R. F., \& Spencer, W. A. Habituation: A model phenomenon for the study of neuronal substrates of behavior. Psychological Review, 1966, 73, 16-43.

VAN Olst, E. H. The orienting reflex. The Hague: Mouton, 1971.

\section{NOTES}

1. The term "recovery" is used to denote either an increase in response amplitude in comparison with a control condition or response evocation following zero responding (habituation).

2. Out of a total of 900 occasions during habituation training on which an offset response could have occurred $(60$ subjects $x$ 15 trials), $316(35 \%)$ of such responses were observed. This frequency seems to be in reasonable agreement with that reported by Stern (1968) for 6-sec tone stimuli. Of the 316 terminal responses, only $15(1.7 \%)$ occurred on the last training trial.

3 . It should be noted, however, that the polygraph records from both experiments were scored by the same experimenter. 